\title{
Estimating the modulatory effects of nanoparticles on neuronal circuits using computational upscaling
}

This article was published in the following Dove Press journal:

International Journal of Nanomedicine

18 September 2013

Number of times this article has been viewed

\section{Michael Busse' \\ David Stevens ${ }^{3}$ \\ Annette Kraegeloh ${ }^{2}$ \\ Christian Cavelius ${ }^{2}$ \\ Mathias Vukelic' \\ Eduard Arzt ${ }^{2}$ \\ Daniel J Strauss ${ }^{1,2}$}

'Systems Neuroscience and Neurotechnology Unit, Saarland University, Faculty of Medicine, Neurocenter, and Saarland University of Applied Sciences, Homburg/ Saarbruecken, Germany; ${ }^{2}$ Leibniz Institute for New Materials, Saarbruecken, Germany; ${ }^{3}$ Department of Physiology, Saarland University, Faculty of Medicine, Homburg/ Saarbruecken, Germany
Correspondence: Daniel J Strauss Saarland University, Faculty of Medicine, Systems Neuroscience and Neurotechnology Unit Neurocenter, Building 90.5, D-6642 I

Homburg/Saarbruecken, Germany

$\mathrm{Tel}+49684$ I I62 409 |

Fax+49684I 1624092

Email strauss@snn-unit.de
Background: Beside the promising application potential of nanotechnologies in engineering, the use of nanomaterials in medicine is growing. New therapies employing innovative nanocarrier systems to increase specificity and efficacy of drug delivery schemes are already in clinical trials. However the influence of the nanoparticles themselves is still unknown in medical applications, especially for complex interactions in neural systems. The aim of this study was to investigate in vitro effects of coated silver nanoparticles (cAgNP) on the excitability of single neuronal cells and to integrate those findings into an in silico model to predict possible effects on neuronal circuits.

Methods: We first performed patch clamp measurements to investigate the effects of nanosized silver particles, surrounded by an organic coating, on excitability of single cells. We then determined which parameters were altered by exposure to those nanoparticles using the Hodgkin-Huxley model of the sodium current. As a third step, we integrated those findings into a well-defined neuronal circuit of thalamocortical interactions to predict possible changes in network signaling due to the applied cAgNP, in silico.

Results: We observed rapid suppression of sodium currents after exposure to cAgNP in our in vitro recordings. In numerical simulations of sodium currents we identified the parameters likely affected by cAgNP. We then examined the effects of such changes on the activity of networks. In silico network modeling indicated effects of local cAgNP application on firing patterns in all neurons in the circuit.

Conclusion: Our sodium current simulation shows that suppression of sodium currents by cAgNP results primarily by a reduction in the amplitude of the current. The network simulation shows that locally cAgNP-induced changes result in changes in network activity in the entire network, indicating that local application of $\mathrm{cAgNP}$ may influence the activity throughout the network.

Keywords: coated silver nanoparticles, modeling, patch clamp recordings, neuronal circuit model, neuromodulatory effect, nanocarriers, nonviral vectors, Llinás model

\section{Introduction}

The areas of application of nanomaterials have increased in the last decade and seem to be unlimited. They range from the application in paints and cosmetics to textiles, foods, food-grade packaging, and various other technical products. The use of nanomaterials in medicine is notable since it comes with high expectations and hopes for treatment of hitherto untreatable diseases. Nanoparticles (NPs) offer a wide range of sizes, morphologies, and surface features that assure potential implementation in drug delivery, diagnostics, and therapy. ${ }^{1}$ A big challenge in current research is to overcome existing drug-delivery barriers, such as biomembranes and the blood-brain 
barrier employing nonviral vectors functioning at the nano-to-micro scale. Those systems could be utilized for the systemic delivery of drugs or genes to target cells for therapy of cancer, inflammation, or for the intended modulation of neural activity in brain tissue., ${ }^{2,3}$

Regarding nanotoxicology, research is in its infancy, and many questions remain unanswered. Studies in biological systems show that the physical parameters of nanosized particles influence their nonspecific absorption in cells and their potential to induce cellular responses. ${ }^{4}$ Existing studies provide limited information in terms of the cellular processes affected by exposure to NPs and their subsequent impact. To understand how NPs of different material, size, and geometry interact with cells, it is necessary to explore the NP-membrane interaction processes on the molecular scale, ie, receptor-binding, endocytosis, and signaling activation. ${ }^{5,6}$ Regarding excitable cells, a starting point is the electrophysiological behavior of cells exposed to NPs. Recent nanotoxicology studies ${ }^{7-9}$ identified (pure) silver nanoparticles (AgNP) as potentially toxic in tissue, especially in neurons. Xu et al, ${ }^{10}$ Zhao et al, ${ }^{11}$ and Lui et $\mathrm{al}^{12}$ examined the influence of nanosized $\mathrm{CuO}, \mathrm{ZnO}$, and $\mathrm{Ag}$ on single neurons in vitro, using the patch clamp method. They observed effects of AgNP on the amplitude and the time course of the sodium current $\left(\mathrm{I}_{\mathrm{Na}}\right)$. The underlying mechanism of the changes in $\mathrm{I}_{\mathrm{Na}}$ was not determined.

We have taken a systems approach to the question of the effects NPs brought into contact to a few cells of a neuronal circuit on network activity of neuronal populations. We carried out patch clamp recordings in neuroendocrine cells and examined the effects of coated silver nanoparticles (cAgNP) on excitability. We observed a suppression of sodium currents and used an established model of dynamic changes in membrane conductance to model the observed changes in $\mathrm{I}_{\mathrm{Na}}$. Based on the fitting results, we computationally reproduced the observed changes in $\mathrm{I}_{\mathrm{Na}}$ parameters in individual neurons and then tested the effects of these changes in a model neuronal network. The outcome of this simplified in silico model serves as initial approximation of in vivo neuromodulatory effects of cAgNP in neuronal circuits.

\section{Material and methods}

The first objective was to determine the electrophysiological effects of cAgNP on single excitable cells. For this purpose we applied cAgNP with an organic coating that prevents particle agglomeration and release of free $\mathrm{Ag}^{+}$, which is suitable for drug delivery. Patch clamp recordings on chromaffin cells were carried out to evaluate the effects of $\mathrm{AgNP}$ on the voltage gated sodium channels (isoform $\mathrm{Na}_{\mathrm{v}}$ 1.7). We applied the Hodgkin-Huxley $(\mathrm{HH})$ model of dynamic changes in membrane conductance ( $\mathrm{HH}$ model $)^{13}$ and computationally fitted this model to our patch clamp data. The utilization of the Differential-Evolution Algorithm (DE) ${ }^{14}$ allowed us an efficient fit of the model to the recorded data. As a consequence, changes in components of the $\mathrm{HH}$ model were observed which shed light on the NP membrane interactions. The altered parameters were applied to modeled neurons within a neuronal feedback circuit. Thus we explored possible effects of those cAgNP on network dynamics in silico, ie, modeling intrinsic single cell dynamics and network oscillations in a circuit by reverting to an extended $\mathrm{HH}-$ type formalism ${ }^{13}$ and dynamic-synaptic coupling, based on an example of the thalamocortical model introduced by Llinás et $\mathrm{al}^{15-18}$ that served as theoretical fundament for the computational implementation. We compared the neuronal response dynamics of the network neurons assuming with and without the interference of cAgNP in specific and nonspecific thalamic cells (STC/NSTC) and in reticular thalamic cells (RTN)(all of isoform $\mathrm{Na}_{\mathrm{v}} 1.2$ ).

\section{Coated silver nanoparticles}

The cAgNP was prepared by thermal decomposition of silver (Ag) oleate and stabilized by oleylamine. These hydrophobic $\mathrm{NP}$ had a mean diameter of $5 \mathrm{~nm} \pm 2 \mathrm{~nm}$. The particles were capped with an amphiphilic polymer (polyethylene glycol) for transfer in aqueous phase and steric stabilization. For further information, see Pellegrino et al. ${ }^{19}$ Prior to use, particles were suspended in ultrapure water and then filtered through a sterile $0.22 \mu \mathrm{m}$ membrane. Inductively coupled plasma atomic emission spectroscopy (ICP-AES) (HORIBA, Jobin Yvon $\mathrm{GmbH}$, Munich, Germany) determination found a total silver content of $1.3 \mathrm{mMol}$ in the resulting nanoparticle dispersion, including a fraction of $0.4 \mu \mathrm{Mol}$ free $\mathrm{Ag}^{+}$. The concentration and the type of molecules and ions on the particle surface lead to electrostatic interaction in the dilution medium, and this changes the coated particles' hydrodynamic diameter to a mean value of $13 \mathrm{~nm} \pm 2 \mathrm{~nm}$ in pure water, $16 \mathrm{~nm} \pm 4 \mathrm{~nm}$ in Roswell Park Memorial Institute cell culture medium (Life Technologies, Carlsbad, CA, USA) and $9 \mathrm{~nm} \pm 1 \mathrm{~nm}$ in $10 \times$ phosphate-buffered saline (PBS) (Life Technologies). A DynaPro Titan instrument (Wyatt Technology Europe $\mathrm{GmbH}$, Dernbach, Germany) was used to perform dynamic light scattering with a laser wavelength of $831 \mathrm{~nm}$. The measured zeta potential (Zetasizer Nano, Malvern Instruments, Malvern, UK) of the nanoparticles was $-69 \mathrm{mV}$ in pure water 
(steric stabilized). Because the solution ingredients bind to the negatively charged particle surfaces, the zeta potential was significantly reduced when dispersed in $10 \times \operatorname{PBS~r~}(-6 \mathrm{mV})$ and Roswell Park Memorial Institute medium $(-16 \mathrm{mV})$.

\section{Chromaffin cell model}

Chromaffin cells are neuroendocrine cells which are well characterized electrophysiologically and are ideally suited for voltage clamp analysis of membrane currents due to their small size and spherical shape. ${ }^{20-22}$ We focused on voltagegated sodium currents which initiate action potentials and propagation in excitable cells. ${ }^{23} \mathrm{Xu}$ et al, ${ }^{10} \mathrm{Zhao}$ et al, ${ }^{11}$ and Lui et $\mathrm{al}^{12}$ tested the influences of $\mathrm{CuO}, \mathrm{ZnO}$, and uncoated AgNP on sodium currents in hippocampal neurons ( $\left.\mathrm{Na}_{\mathrm{v}} 1.2\right)$ by using the patch clamp method. They found effects of AgNP on the amplitude and the time course of the sodium current $\left(\mathrm{I}_{\mathrm{Na}}\right)$ in their experiments. Since we observed similar findings on chromaffin $\mathrm{Na}_{\mathrm{v}} 1.7$ channels, it is likely that this effect is not $\mathrm{Na}_{\mathrm{v}}$ isoform specific. This is consistent with the fact that the $\mathrm{Na}_{\mathrm{v}}$ isoforms in hippocampal cells $\left(\mathrm{Na}_{\mathrm{v}} 1.1\right.$ and 1.2) and in chromaffin cells $\left(\mathrm{Na}_{\mathrm{v}} 1.7\right)$ have an amino acid sequence similarity of about $95 \%$ and show nearly identical electrophysiological behavior. ${ }^{23-28}$ We employed our findings on $\mathrm{Na}_{\mathrm{v}} 1.7$ channels for the modeling approach, in which we devolve the measured effects of cAgNP on chromaffin cell voltage-gated sodium currents, to voltage-gated sodium channels of thalamic neurons (STC, NSTC, RTN).

For cell preparation, the adrenal glands from 1-day-old to 3-day-old mice were collected and digested with 20 units of papain (Worthington Biochemical Corp, Lakewood, NY, USA) at $37^{\circ} \mathrm{C}$ for 25 minutes to 30 minutes. After trituration, cells were plated on $25 \mathrm{~mm}$ cover glasses and then incubated at $37^{\circ} \mathrm{C}$ and $8 \% \mathrm{CO}_{2}$. Chromaffin cells were kept in culture medium (ITS-X, DMEM with GlutaMax and 100 units penicillin/streptomycin; Life Technologies), prior to recordings $12-48$ hours later.

\section{Patch clamp measurements}

Patch clamp measurements in the whole-cell configuration were carried out with 3-6M $\Omega$ pipettes using an EPC-9 patch clamp amplifier controlled by PULSE software (HEKA Instruments Inc, Lambrecht, Germany). Sodium current measurements were performed on both cAgNP exposed and naïve cells at a holding potential of $-70 \mathrm{mV}$ at room temperature. The measurement procedure was the following: In a new dish, four control cells were recorded first; each recording comprised around ten depolarizations to $-10 \mathrm{mV}$ with the step duration of $30 \mathrm{~s}$. While the last control cell patch was still active, the cAgNP dispersion was pipetted into the chamber and then effects on the patched cell could be measured. Afterward, the sodium currents of three to five more cells from the treated dish were collected. This procedure was repeated for concentrations of $13 \mu \mathrm{Mol}, 16 \mu \mathrm{Mol}$, $43 \mu \mathrm{Mol}, 130 \mu \mathrm{Mol}$, and $1.3 \mathrm{mMol}$, respectively. As diluent, the extracellular solution (HEPES-buffered saline solution) was utilized. Altogether, the current traces of 70 control and 45 cAgNP-exposed chromaffin cells were recorded. The extracellular solution contained $145 \mathrm{mM} \mathrm{NaCl} ; 2.4 \mathrm{mM} \mathrm{KCl}$; $10 \mathrm{mM}$ HEPES; $1.2 \mathrm{mM} \mathrm{MgCl}_{2} ; 2.5 \mathrm{mM} \mathrm{CaCl}_{2}$; and $10 \mathrm{mM}$ glucose ( $\mathrm{pH}$ 7.5). The pipette solution contained $135 \mathrm{mM}$ Cs-aspartate; 10 mM Cs-HEPES; 5 mM Cs-ethylene glycol tetraacetic acid (EGTA); $3 \mathrm{mM} \mathrm{CaCl}_{2} ; 1 \mathrm{mM} \mathrm{MgCl}_{2} ; 2 \mathrm{mM}$ Mg-ATP; and $0.3 \mathrm{mM} \mathrm{Na}_{2}-\mathrm{GTP}$ (pH 7.2).

\section{$\mathrm{HH}$ fitting employing Differential Evolution Algorithm}

We fit $\mathrm{I}_{\mathrm{Na}}$ from the patch clamp data with the $\mathrm{HH}$ model ${ }^{13}$ to determine which parameters might be modified under the influence of cAgNP. Those factors directly link to physiological mechanisms involved in action potential generation. The basic $\mathrm{HH}$ equations ${ }^{29}$ are given by:

$$
\begin{aligned}
G_{N a}=G_{N a m a x} m^{3} h \frac{d m}{d t} & =\alpha_{m}(1-m)-\beta_{m} m \\
\frac{d h}{d t} & =\alpha_{h}(1-h)-\beta_{h} h
\end{aligned}
$$

for the conductance of sodium ions at the experimental conditions of $\mathrm{HH}^{13}$ with a maximum sodium conductance of

$$
\mathrm{G}_{\mathrm{Namax}}=120 \mathrm{mS} / \mathrm{cm}^{2}
$$

The corresponding empirical theorems for the transferrate coefficients are:

$$
\begin{aligned}
& \alpha_{\mathrm{m}}=\frac{2.5-0.1 \mathrm{~V}^{\prime}}{\mathrm{e}^{2.5-0.1 \mathrm{~V}^{\prime}}-1} \frac{1}{\mathrm{~ms}} \\
& \beta_{\mathrm{m}}=\frac{4}{\mathrm{e}^{\mathrm{V}^{\prime} / 18}} \quad \frac{1}{\mathrm{~ms}} \\
& \alpha_{\mathrm{h}}=\frac{0.07}{\mathrm{e}^{\mathrm{V}^{\prime} / 20}} \quad \frac{1}{\mathrm{~ms}} \\
& \beta_{\mathrm{h}}=\frac{1}{\mathrm{e}^{30-\mathrm{V}^{\prime} / 10}+1} \quad \frac{1}{\mathrm{~ms}}
\end{aligned}
$$

with $\mathrm{V}^{\prime}=\mathrm{Vm}-\mathrm{Vr}[\mathrm{mV}]$, where $\mathrm{Vm}$ is the actual membrane voltage and $\mathrm{Vr}$ is the resting voltage.

Using a voltage clamp ${ }^{30}$ for a voltage step, the transfer-rate coefficients $\alpha_{m}, \beta_{m}, \alpha_{h}$, and $\beta_{h}$ change instantly to new values 
(in steady state). As in steady state, the transfer-rate coefficients in Equation 3 are constant, so the primary differential equation can be readily solved for $\mathrm{m}$ and $\mathrm{h}$, giving:

$$
\mathrm{m}(\mathrm{t})=\mathrm{m}_{\infty}-\left(\mathrm{m}_{\infty}-\mathrm{m}_{0}\right) \mathrm{e}^{\frac{-\mathrm{t}}{\mathrm{Tm}}}
$$

where

$$
\mathrm{m}_{\infty}=\frac{\alpha_{\mathrm{m}}}{\alpha_{\mathrm{m}}+\beta_{\mathrm{m}}}
$$

represents the value of $m$ and

$$
\tau_{\mathrm{m}}=\frac{1}{\alpha_{\mathrm{m}}+\beta_{\mathrm{m}}}
$$

defines the time constant in [s] in steady state.

The mathematical term of $\mathrm{h}$ is similar to the $\mathrm{m}$ in Equation 4. By applying voltage clamp, a voltage step initiates an exponential change in $\mathrm{m}$ (and $\mathrm{h}$ ) from its initial value of $\mathrm{m}_{0}\left(\right.$ or $\left.\mathrm{h}_{0}\right)$ at $\mathrm{t}=0 \mathrm{~s}$ toward the steady-state value of $\mathrm{m}_{\infty}\left(\right.$ or $\left.\mathrm{h}_{\infty}\right)$ at $\mathrm{t}=\infty \mathrm{s}$. Finally, the sodium current $\mathrm{I}_{\mathrm{Na}}$ that has to be fitted is then given by:

$$
\mathcal{I}_{\mathrm{Na}}=\mathrm{G}_{\mathrm{Na}} \cdot\left(\mathrm{V}_{\mathrm{m}}-\mathrm{V}_{\mathrm{Na}}\right) \frac{\mathrm{nA}}{\mathrm{cm}^{2}},
$$

where $\mathrm{V}_{\mathrm{Na}}[\mathrm{mV}]$ expresses the resulting Nernst - or also called reversal-potential - following the equation of Nernst, simplified for this issue to:

$$
\mathrm{V}_{\mathrm{Na}}=\phi_{\mathrm{i}}-\phi_{\mathrm{o}}
$$

with $\phi_{\mathrm{i}}=$ intracellular and $\phi_{\mathrm{o}}=$ extracellular potential (ion concentration dependent).

Various problems in applied mathematics have target functions that are noncontinuous, nonlinear, nondifferentiable, flat, noisy, multidimensional, or have many local minima, constraints, or stochasticity. Fitting the steady-state $\mathrm{HH}$ model (Equations 1-7) to the measured patch clamp data requires the solution of a high dimensional inverse problem: Since the essential HH model equations that need to be taken into account for the fitting consist of 13 independent parameters (constants evaluated by $\mathrm{HH}$ ) that have to be estimated, this problem cannot be solved analytically.

Approximate solutions can be achieved by the Differential-Evolution (DE) Algorithm, a technique that originates from the genetic annealing algorithm, introduced by Price et al ${ }^{14}$ in 1996 . This invention offers a global optimization method by stochastic, population-based optimization and can be utilized to optimize real parameters and real valued functions, such as the 13 parameters in the HH modelfitting problem. A detailed description of the algorithm can be found in Price et al. ${ }^{14}$

In terms of the introduced fitting problem, the DE Algorithm was implemented to minimize the distance between the measured sodium current and the one iteratively calculated by the $\mathrm{HH}$ model. As a consequence, the parameters for the best fit were evaluated. The 13 parameters, that give the freedom for the curve-fitting process, represent all the empirical coefficients in Equations 1-7 that were estimated by $\mathrm{HH}$ in their experiments in $1952 .{ }^{13}$ The following equations indicate again the applied $\mathrm{HH}$ formulations, but now with the 13 free parameters expressed by $\xi_{{ }_{1}}-\xi_{\cdot_{13}}$ :

$$
\begin{aligned}
& \alpha_{\mathrm{h}}=\frac{\xi .1}{\mathrm{e}^{\mathrm{V}^{\prime} / \xi .2}} \frac{1}{\mathrm{~ms}} \\
& \beta_{\mathrm{h}}=\frac{1}{\mathrm{e}^{\xi .3-\mathrm{V}^{\prime} / \xi .4}+\xi .5} \frac{1}{\mathrm{~ms}} \\
& \alpha_{\mathrm{m}}=\frac{\xi .6-\xi .7 \cdot \mathrm{V}^{\prime}}{\mathrm{e}^{\xi .6-\xi .7 \cdot \mathrm{V}^{\prime}}-\xi .8} \frac{1}{\mathrm{~ms}} \\
& \beta_{\mathrm{m}}=\frac{\xi .9}{\mathrm{e}^{\mathrm{V}^{\prime} / \xi .10}} \frac{1}{\mathrm{~ms}} \\
& \mathrm{G}_{\mathrm{Na}}=\xi .11 \cdot \mathrm{m}^{3} \mathrm{~h} \\
& \mathrm{I}_{\mathrm{Na}}=\mathrm{G}_{\mathrm{Na}} \cdot\left(\mathrm{V}_{\mathrm{m}}-\xi .12\right)
\end{aligned}
$$

and, lastly, the point of time for the start of the depolarization $\mathrm{t}_{\text {stim }}$ as $\xi .13$.

\section{Thalamocortical interactions}

The thalamus provides the major route for afferents to the neocortex and extrasensory regions of the brain. The traditional concept treating the thalamus as the sensory gateway to the cortex is an oversimplification, because the cerebral cortex receives input not only from the sensespecific nuclei but also from the nonspecific thalamic nuclei, which have multimodal connections to the cortex, probably governing overall arousal. ${ }^{31}$ With respect to the interactions between the specific and nonspecific thalamic loops, Llinás et al suggested that, rather than a gate, the thalamus is a hub from which any area in the cortex can communicate with any other. ${ }^{17}$ Bidirectionality is the most remarkable feature of this thalamocortical connectivity. Thalamic nuclei receive reciprocal connections from the cortical areas that they project to, though the number of corticothalamic fibers is significantly greater than the number of thalamocortical axons. ${ }^{31,32}$ These reciprocal thalamocortical connections create bidirectional neuronal loops between the thalamus and 
the cortex. Consequently, distributed neural representations of simultaneous perceptual events or features could be related to each other within the thalamocortical system. Binding input from different sensory modalities into a single cognitive event is assumed to be a consequence. The underlying mechanism has been proposed as temporal binding, a process based on the synchronization of neural signals. ${ }^{33}$ Different studies have shown that certain types of cognitive functions are intimately related to synchronized neuronal oscillations at both low (4-7/8-13 Hz) and high (18-35/30-70 Hz) frequencies. ${ }^{18,34-38}$ The activity patterns of these oscillations are formed within one or more bounded areas (corresponding to cortical columns). ${ }^{17,18,39}$ A subset of the employed cortical neurons can generate repetitive, high-frequency burst discharges, referred to as chattering cells. Those can generate bursts with intraburst frequencies of $\sim 300-750 \mathrm{~Hz}$ and interburst frequencies of $\sim 8-80 \mathrm{~Hz} \cdot{ }^{40-42}$ We focused on the thalamocortical activity of those chattering cells since their firing patterns in burst mode contain more information, to evaluate the impact of NP on the circuit's activity.

\section{Applied thalamocortical network}

The simplified in silico model that we used to predict in vivo behavior is based on the detailed model of thalamocortical interaction and binding suggested by Llinás et al. ${ }^{15-18}$ More information about the Llinás model as a basis for the developed corticothalamic network can be found in the supplementary materials. The principal result of this model is that the intrinsic electrical properties of neurons and the dynamic events resulting from their connectivity cause global resonant states. Resonant states in the network will change due to small alterations in the neural signaling characteristics. The applied circuit is based on kinetic models of pyramidal neurons (here: chattering cells, PY), ${ }^{43-46}$ inhibitory cortical interneurons (IN), ${ }^{45,47}$ thalamic cells (TC) including specific thalamic cells and nonspecific thalamic cells, ${ }^{48-50}$ and reticular thalamic neurons. ${ }^{43,45,51,52}$ Each single neuron model is considered as one compartment (except PY, modeled as two compartments) and is represented by coupled differential equations, according to an extended $\mathrm{HH}$-type scheme. ${ }^{13}$ The scheme of synaptic connectivity in the developed simplified thalamocortical network model is represented by Figure 1. In this model, specific thalamic inputs are represented by a thalamic neuron (STC) that projects to both PY neuron and inhibitory cortical interneurons located in cortical layer 4, after sending axon collaterals to the RTNs. The NSTC represents intralaminar, nonspecific thalamic inputs, and projects to neocortical layer 1 after sending axon collaterals

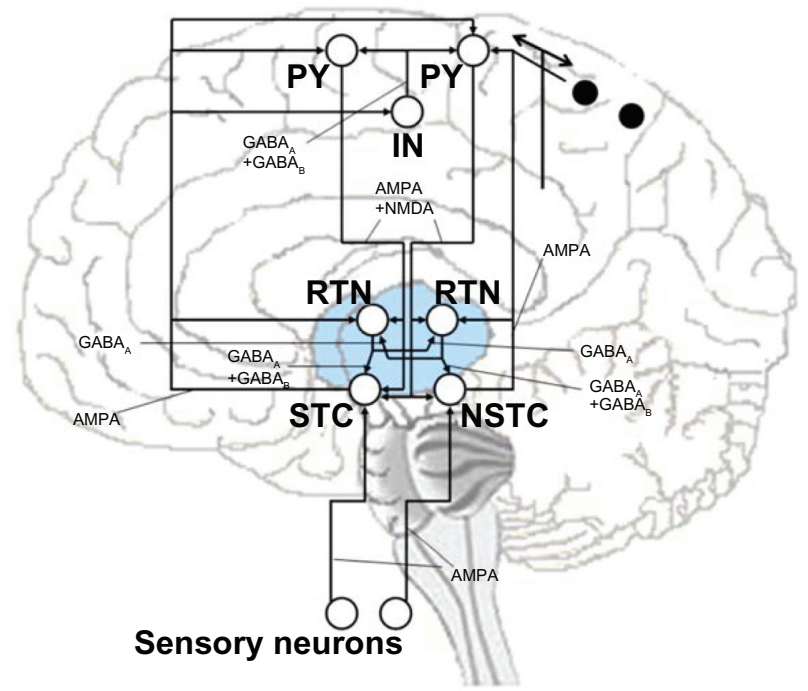

Figure I Schematic description of synaptic interconnections in the simplified computational model of the thalamocortical network.

Abbreviations: IN, interneurons; RTN, reticular thalamic cells; PY, pyramidal neurons; STC, specific thalamic cells; NSTC, nonspecific thalamic cells.

to the reticular thalamic neurons. Specific thalamic cells and nonspecific thalamic cell neurons generate excitatory postsynaptic potentials that are mediated by fast excitatory receptors in the model. RTNs project with inhibitory characteristic to specific and intralaminar nucleus neurons. Inhibitory fast and slow receptors in the thalamic neurons both mediate the inhibitory postsynaptic potentials of those cells. The RTN neurons also have reciprocal inhibitory synaptic connectivity. The corresponding activity is mediated by fast inhibitory receptors.

In the model, the cerebral cortex was considered as a simple network model of inhibitory IN and excitatory PY neurons. ${ }^{15-18}$ Although this is a highly simplified representation of the neocortex's multilayered structure, no additional complexity was required for the theoretical modeling. Consequently, the pyramidal neurons in layers 4 and 5 are described by single neurons (Figure 1) that receive inputs and project to both STC and NSTC cells and have axon collaterals to the RTN neurons. In the model, four PY neurons were included, two of which receive input from the STC to provide specific sensory input to the cortex. This structure represents the specific resonant loop as is shown in Figure 1 on the left. The right side of Figure 1 indicates the nonspecific resonant loop, where three PY neurons receive their inputs in a more diffuse way from NSTC to provide the multimodal connectivity to the cortex. The two black spots represent two PY neurons that receive inputs and project back to the NSTC. In this model, the corticofugal excita- 
tion of the PY is mediated by both fast and slow excitatory receptors. In the circuit, all PY neurons receive axons from the cortical inhibitory IN, in which the inhibitory postsynaptic potential elicited by this cell is also mediated by both fast and slow excitatory receptors. Lastly, the essential sensory inputs to activate STC and NSTC are provided by including two sensory neurons in the present model (Figure 1). Thus, the synaptic projections from those sensory neurons activate the fast receptors of the thalamic nuclei. Every neuron of the simplified thalamocortical model receives various synaptic inputs that are modeled as the sum over all synaptic currents that each cell receives. ${ }^{53,54}$ Accordingly, every neuron is described by the generic membrane equation:

$$
\mathrm{C}_{\mathrm{m}} \frac{\mathrm{dV} \mathrm{V}_{\mathrm{i}}}{\mathrm{dt}}=-\underbrace{\overline{\mathrm{g}}_{\mathrm{L}}\left(\mathrm{V}_{\mathrm{i}}-\mathrm{E}_{\mathrm{L}}\right)}_{\text {leakageterm }}-\sum_{\mathrm{j}} \mathrm{I}_{\mathrm{ji}}^{\mathrm{int}}-\sum_{\mathrm{k}} \mathrm{I}_{\mathrm{ki}}^{\mathrm{syn}}
$$

where $\mathrm{C}_{\mathrm{m}}$ is the specific membrane capacity and $\mathrm{V}_{\mathrm{i}}$ is the postsynaptic membrane potential. $\mathrm{I}_{\mathrm{ji}}^{\mathrm{int}}$ and $\mathrm{I}_{\mathrm{ki}}^{\text {syn }}$ signify the intrinsic (ionic) and synaptic currents. The generic form of the intrinsic currents (generalization of Equation 7) is represented by:

$$
\mathrm{I}_{\mathrm{ji}}^{\mathrm{int}}=\overline{\mathrm{g}}_{\mathrm{j}} \mathrm{m}_{\mathrm{j}}^{\mathrm{M}} \mathrm{h}_{\mathrm{j}}^{\mathrm{N}}\left(\mathrm{V}_{\mathrm{i}}-\mathrm{E}_{\mathrm{j}}\right)
$$

Here, $\mathrm{i}$ denotes the postsynaptic neuron, and $\mathrm{j}$ stands for the specific ionic type. Further, $g_{j}$ is the maximal conductance, $m$ the time and voltage dependent activation variable, $h$ is the corresponding (time and voltage dependent) inactivation variable and finally $\left(\mathrm{V}_{\mathrm{i}}-\mathrm{E}_{\mathrm{j}}\right)$ is the difference between membrane potential and reversal potential of each ion. The following generic equation represents the synaptic currents in the system:

$$
\mathrm{I}_{\mathrm{ki}}^{\mathrm{syn}}=\overline{\mathrm{g}}_{\mathrm{ki}} \mathrm{s}_{\mathrm{ki}}\left(\mathrm{V}_{\mathrm{i}}-\mathrm{E}_{\mathrm{ki}}\right)
$$

where $\mathrm{k}_{\mathrm{i}}$ designates the synaptic junction from the presynaptic neuron $\mathrm{k}$ to the postsynaptic neuron $\mathrm{i}, \mathrm{g}_{\mathrm{ki}}$ is the maximal conductance of the postsynaptic receptors, and $\mathrm{E}_{\mathrm{ki}}$ is the reversal potential. The fraction of open receptors is specified by $\mathrm{s}_{\mathrm{ki}}$, according to the simple two-state scheme:

$$
\text { (closed })+T\left(V_{k}\right) \underset{\leftarrow}{\stackrel{\alpha}{\rightleftarrows}} \text { (open), }
$$

For computational efficiency, a reduced transmitter release model is used, assuming all intervening reactions in the release process are relatively fast and thus can be considered in steady state (instantaneous). ${ }^{55}$ Consequently, the stationary relationship between the transmitter concentration $(\mathrm{T})$ and presynaptic voltage is described by a simple sigmoidal function: ${ }^{55}$

$$
[\mathrm{T}]\left(\mathrm{V}_{\mathrm{pre}}\right)=\frac{\mathrm{T}_{\max }}{1+\exp \left(-\left(\mathrm{V}_{\text {pre }}-\mathrm{V}_{\mathrm{p}}\right) / \mathrm{K}_{\mathrm{p}}\right)}
$$

where $T_{\max }$ is the maximal concentration of transmitter in the synaptic cleft, $\mathrm{V}_{\text {pre }}$ is the presynaptic voltage, $\mathrm{K}_{\mathrm{p}}$ gives the steepness and $V_{p}$ sets the value at which the function is half activated. This form, in conjunction with simple kinetic models of postsynaptic channels, provides a model of synaptic interaction based on autonomous differential equations with only one or two variables..$^{56,57}$

In the model, all initial conditions and set parameters representing a single cell or synaptic connection come from electrophysiological measurements on the specific neurons taken from cited references. Wang et al, ${ }^{43,56}$ Golomb et al, ${ }^{46}$ and Destexhe et al ${ }^{55,58}$ contain detailed descriptions of the particular equations and the corresponding cell- and transmitter-specific parameters. According to Destexhe et al, ${ }^{53}$ different values of $\mathrm{I}_{\mathrm{h}}$ and $\mathrm{I}_{\mathrm{KL}}$ would cause heterogeneity in the intrinsic properties of the cells. Therefore, the intrinsic conductance of $g_{h}$ and $g_{K L}$ for the STC and the NSTC and $\mathrm{g}_{\mathrm{KL}}$ for the RTN neuron models are slightly different in the present model.

To simulate the effects of $\mathrm{cAgNP}$ in contact with thalamic cells, ie, STC, NSTC, and RTN, respectively, the changes of the intrinsic currents that we identified by fitting our patch clamp data to the $\mathrm{HH}$ model were applied to those cells. The kinetics and voltage dependence of the modeled currents are very similar to the currents measured in patch clamp experiments (see the chromaffin cell model section). MATLAB was used as the simulation environment, in which the differential equations were solved by employing a fourthorder Runge-Kutta method.

\section{Results}

The results of measurements of sodium current amplitudes are shown in Table 1. Averages (medians) ( $\mathrm{x})$ and standard deviations $(\sigma)$ in $\mathrm{I}_{\mathrm{Na}}$ amplitudes before and after cAgNP addition and differences in median $(\Delta \tilde{\mathrm{x}})$ between controls and $\mathrm{cAgNP}$ exposed cells at different concentrations are represented there. Since the amplitudes of the controls (base line) vary, the values have been normalized. Table S1 indicates the amplitudes of $\mathrm{I}_{\mathrm{Na}}$ before and after $\mathrm{cAgNP}$ addition as total values.

The attenuation of the amplitude occurred rapidly after the application of the cAgNP and was then recorded in another three to five cells in the treated dish. Suppression of $\mathrm{I}_{\mathrm{Na}}$ was observed in 43 of 45 experiments. In another group of experiments, cAgNP (16 $\mu \mathrm{M})$ were applied locally via an application pipette to chromaffin cells after the recording of control 
Table I Normalized amplitudes of $\mathrm{I}_{\mathrm{Na}}$ before and after cAgNP addition (holding potential $-70 \mathrm{mV}$; depolarization potential -20 mV)

\begin{tabular}{llllll}
\hline $\begin{array}{l}\text { cAgNP } \\
\text { concentration }\end{array}$ & $\begin{array}{l}\tilde{\mathbf{x}}^{\mathrm{a}} \text { before cAgNP } \\
\text { normalized }\end{array}$ & $\begin{array}{l}\tilde{\mathbf{x}} \text { after cAgNP } \\
\text { normalized }\end{array}$ & $\begin{array}{l}\sigma^{\mathrm{b}} \text { before cAgNP } \\
\text { normalized }\end{array}$ & $\begin{array}{l}\sigma^{\mathrm{b}} \text { after cAgNP } \\
\text { normalized }\end{array}$ & $\begin{array}{l}\Delta \tilde{\mathbf{x}}^{\mathrm{c}} \\
\text { normalized }\end{array}$ \\
\hline $\mathrm{I} 3 \mu \mathrm{Mol}(\mathrm{I} / \mathrm{IO0})$ & $\mathrm{I}$ & $0.9 \mathrm{I}$ & 0.14 & 0.12 & 0.09 \\
$\mathrm{I} 6 \mu \mathrm{Mol}(\mathrm{I} / 80)$ & $\mathrm{I}$ & 0.77 & 0.19 & $0.1 \mathrm{I}$ & 0.23 \\
$43 \mu \mathrm{Mol}(\mathrm{I} / 30)$ & $\mathrm{I}$ & 0.52 & 0.18 & 0.09 & 0.48 \\
$\mathrm{I} 30 \mu \mathrm{Mol}(\mathrm{I} / \mathrm{IO})$ & $\mathrm{I}$ & 0.47 & 0.13 & 0.10 & 0.53 \\
$\mathrm{I} .3 \mathrm{mMol}(\mathrm{I} / \mathrm{I})$ & $\mathrm{I}$ & $0.3 \mathrm{I}$ & 0.13 & 0.23 & 0.69 \\
\hline
\end{tabular}

Note: ${ }^{a} \tilde{x}=$ Normalized average amplitude; ${ }^{b} \sigma=$ normalized standard deviation; ${ }^{c} \Delta \tilde{x}=$ normalized difference between controls and $c A g N P$ exposed cells. Abbreviations: cAgNP, coated silver nanoparticles; $\mathrm{mV}$, millivolt.

action potentials. Current voltage relationships were recorded under control conditions and after application of cAgNP. Figure 2 shows a representative experiment. Figure 2A shows the current-voltage relation fit, and Figure 2B shows single depolarizations to $-0 \mathrm{mV}$, which were applied to track changes in sodium current amplitude. $\mathrm{I}_{\mathrm{Na}}$ was reduced within seconds of application with maximal block occurring after about two minutes. In some cases, substantial recovery occurred within 10 minutes of application. There was no significant shift in the voltage-dependence of the $\mathrm{I}_{\mathrm{Na}}(3.1 \pm 2.6 \mathrm{mV}$, mean $\pm \mathrm{SD})$ and no significant shift in the null potential of $\mathrm{I}_{\mathrm{Na}}(39 \pm 5.1$ $\mathrm{mV}$ and $44 \pm 4.9 \mathrm{mV}$; mean $\pm \mathrm{SD}$ ).

Five representative sodium current curves taken after the application of $\mathrm{cAgNP}$ and their corresponding controls from the $1.3 \mathrm{mM}$ dataset have been selected for the DE fitting procedure. Before processing, a cubic spline interpolation was employed to smooth the curves, to reduce noise, and produce consistent vector length. Figure 3 shows representative sodium currents as continuous lines. Figure 3A shows a control sodium current. The right panel (Figure 3B) shows the sodium current of the same cell after the addition of cAgNP.

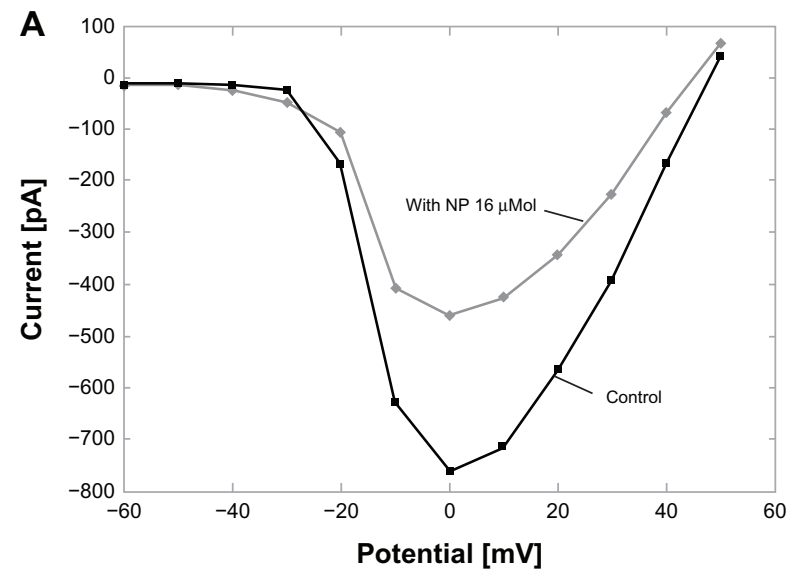

The dashed lines in Figure 3 represent the corresponding model fittings to these curves by the DE Algorithm. The fitting process generated estimates of the 13 free coefficients $(\xi)$ in Equations 9 and 10. There were conspicuous changes in parameters $\xi_{1,2,6,7,8,9,10 \text {, and } 12}$ (Equations 9 and 10). By transferring those findings back into a more macroscopic (transfer-rate coefficients) level of the $\mathrm{H}$ equations, the transfer-rate coefficients $\alpha_{\mathrm{h}}, \alpha_{\mathrm{m}}, \beta_{\mathrm{m},}$ and the reversal potential $\mathrm{V}_{\mathrm{Na}}$ (Equation 9 and Equation 10) were found to be potentially modified. Since the reduction in amplitude of $\mathrm{I}_{\mathrm{Na}}$ occurred without an appreciable shift in either activation voltage or null potential, it is unlikely that a change in $\mathrm{V}_{\mathrm{Na}}$ is involved in the effects of $\mathrm{cAgNP}$ on $\mathrm{I}_{\mathrm{Na}}$. We therefore fixed $\mathrm{V}_{\mathrm{Na}}$ and ran the simulation again. As expected, very good fits could be achieved when only changes in the transfer-rate coefficients $\alpha_{h}, \alpha_{m}$, and $\beta_{m}$ were allowed. Figure 4 shows the changes of these variables after particle exposition in a normalized bar diagram. Changes in these parameters were required for a good fit to the cAgNP data.

Figure 5 shows the output of a representative sodium current fit with the relevant parameter changes (dashed lines). To estimate the impact of cAgNP on the activity in a neuronal

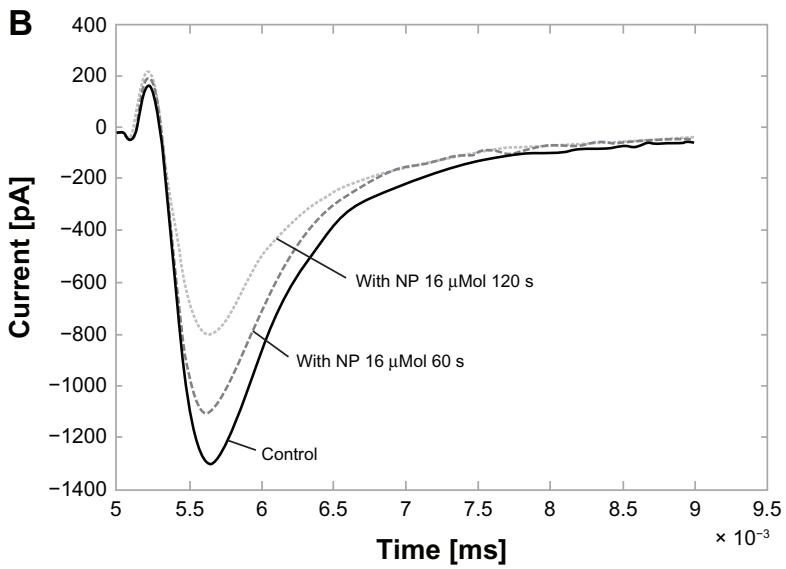

Figure 2 Local application of cAgNP to chromaffin cells. (A) A representative currrent-voltage (IV)-curve of a cell before and after application of cAgNP (I6 $\mu$ Mol, gray; corresponding control, black). (B) Records of $\mathrm{I}_{\mathrm{Na}}$ before and after local application of cAgNP after 60 seconds (s) and $I 20$ seconds. Abbreviations: $\mathrm{cAgNP}$, coated silver nanoparticles; $\mathrm{I}_{\mathrm{Na}}$, sodium current; $\mathrm{ms}$, milliseconds; $\mathrm{mV}$, millivolt; $\mathrm{NP}$, nanoparticles; $\mathrm{pA}$, picoampere. 

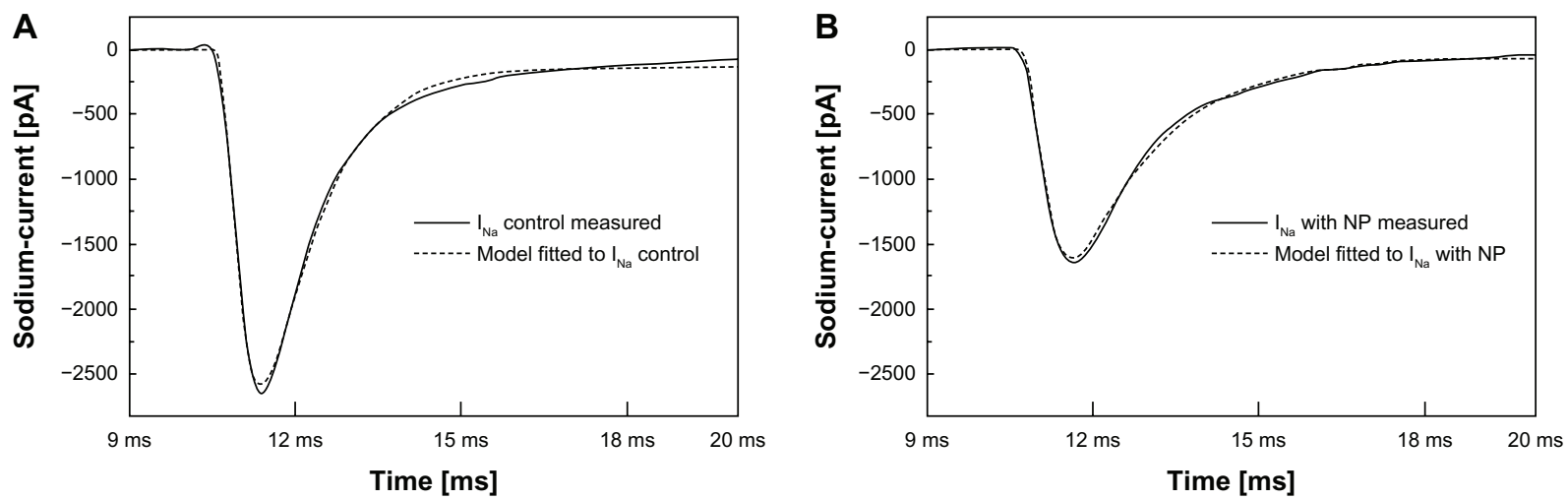

Figure 3 Measured sodium current. Measured sodium current without (A) and with (B) cAgNP (solid lines, holding potential $-70 \mathrm{mV}$, depolarization potential $-20 \mathrm{mV}$ ), and the curve fits by DE (dashed lines).

Abbreviations: pA, picoampere; $I_{\mathrm{Na}}$, sodium current; cAgNP, coated silver nanoparticles; NP, nanoparticles; DE, Differential-Evolution Algorithm.

feedback circuit, the simulated results of the first model were employed to modify the properties of $\mathrm{I}_{\mathrm{Na}}$ of thalamic cells of the network model of corticothalamic interactions. The initial conditions for all gating variables of each neuron model involved were calculated, according to their steady-state functions, whereas the membrane potential's initial conditions were taken from cited references. To activate the feedback circuit, a single action potential was generated in the model sensory neuron which directly projects to STC by utilizing a brief depolarization current pulse of $\mathrm{I}_{\text {app }}=6 \mu \mathrm{A} / \mathrm{cm}^{2}$. This leads to a small depolarization in STC and as a consequence of the specific synaptic parameters, all neurons fire in a $6-8 \mathrm{~Hz}$ bursting oscillation mode. The resulting membrane potentials of the cortical PY neuron 1, 2, 3, and 4 are shown in Figure 6 for a time interval of 4 seconds.

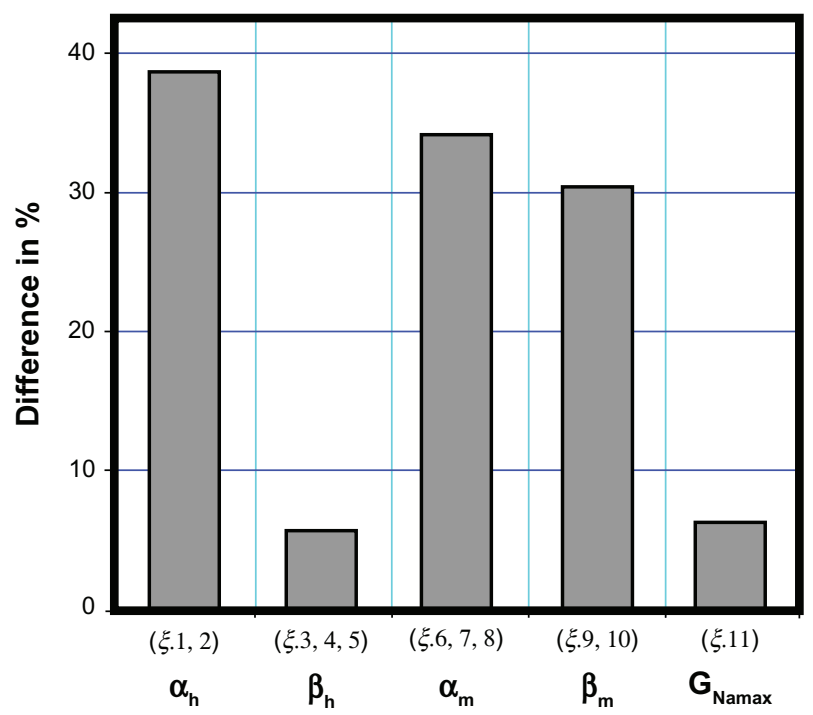

Figure 4 Differences in percentages.

Notes: Differences of model fitted $\alpha_{h}, \beta_{h}, \alpha_{m}, \beta_{m}$, and $G_{\text {Namax }}$ between the measured sodium current with cAgNP in $130 \mu \mathrm{Mol}$ concentration and the corresponding controls. The $\xi .13$ (stim-time) is not considered.

Abbreviation: $\mathrm{cAgNP}$, coated silver nanoparticles.
Figure 7 illustrates the resulting membrane potentials of the cortical inhibitory IN, RTN1, RTN2, STC, and the NSTC neuron for 4 seconds. The black graphs in both figures show the behavior of the engaged cells after the initial AP in the sensory neuron under normal physiological conditions.

The gray lines show the behavior of the same cells in the network after altering $\mathrm{I}_{\mathrm{Na}}$ of thalamic cells, ie, NSTC, STC, and RTNs consistent with the changes in $\mathrm{I}_{\mathrm{Na}}$ observed after cAgNP application. Variations in the firing patterns of all cells embedded in the simplified network model were apparent after this manipulation. Changes in activity can be seen in Table 2 as mean values, including the corresponding standard deviations $(\sigma)$ for interburst intervals, the resulting interburst frequencies and the intraburst frequencies before and after hypothesized cAgNP presence in thalamic cells for 4 seconds (only the bursting neurons were considered for the statistics).

Table 2 reveals that the interburst frequencies are slightly increased after cAgNP application in the thalamus core. The intraburst frequencies are found to be slightly decreased for PY1, PY2, and for IN. In contrast, the intraburst frequencies for both RTN1 and RTN2 are slightly increased whereas the intraburst frequency for PY4 is more than doubled after NP addition.

\section{Discussion}

The patch clamp measurements show that the application of cAgNP to chromaffin cells reduces the amplitude of sodium currents. The changes were rapid, partially reversible and dose-dependent. Based on the HH fitting, the cAgNP may affect the electrically charged $\mathrm{h}$-particles by the alteration to the noninactivating (toward open) state at changed transferrate coefficient $\alpha_{h}$. Additionally, the $\mathrm{m}$-particles are influenced by the transition to the open and closed state as $\alpha_{\mathrm{m}}$ plus $\beta_{\mathrm{m}}$ is 

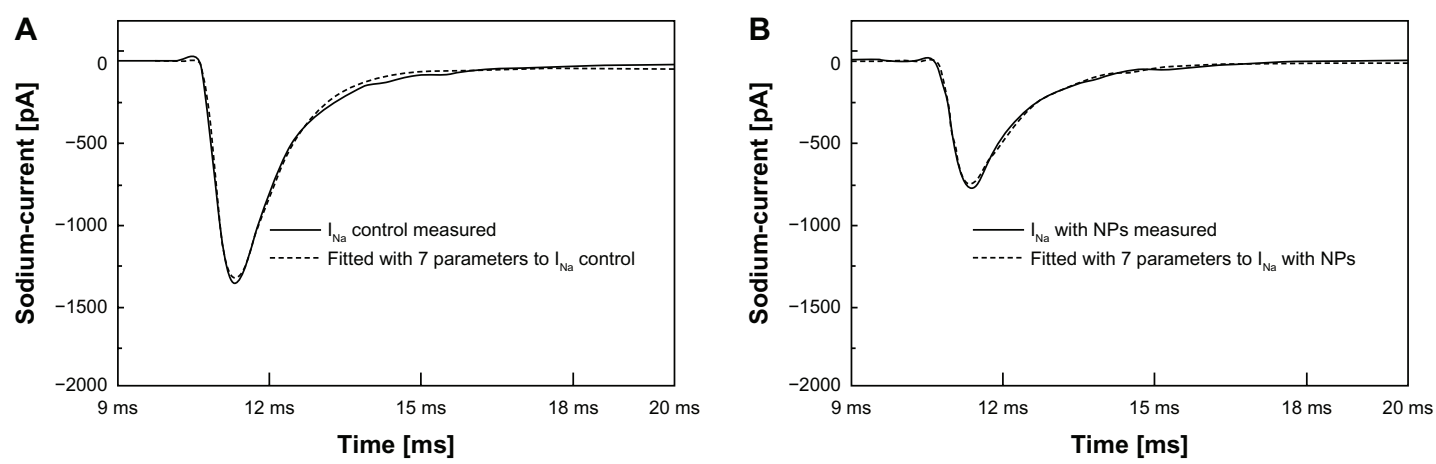

Figure 5 Currents for control. DE fittings (dashed lines) utilizing just the seven identified Hodgkin-Huxley equation parameters $\left(\alpha_{\mathrm{h}}, \alpha_{\mathrm{m}}\right.$, and $\left.\beta_{\mathrm{m}}\right)$ and the corresponding electrophysiologically measured currents for control (A) and cAgNP ( $130 \mu \mathrm{Mol})$ transfected (B).

Abbreviations: $\mathrm{pA}$, picoampere; $\mathrm{I}_{\mathrm{Na}}$, sodium current; cAgNP, coated silver nanoparticles; NP, nanoparticles; DE, Differential-Evolution Algorithm; ms, milliseconds.
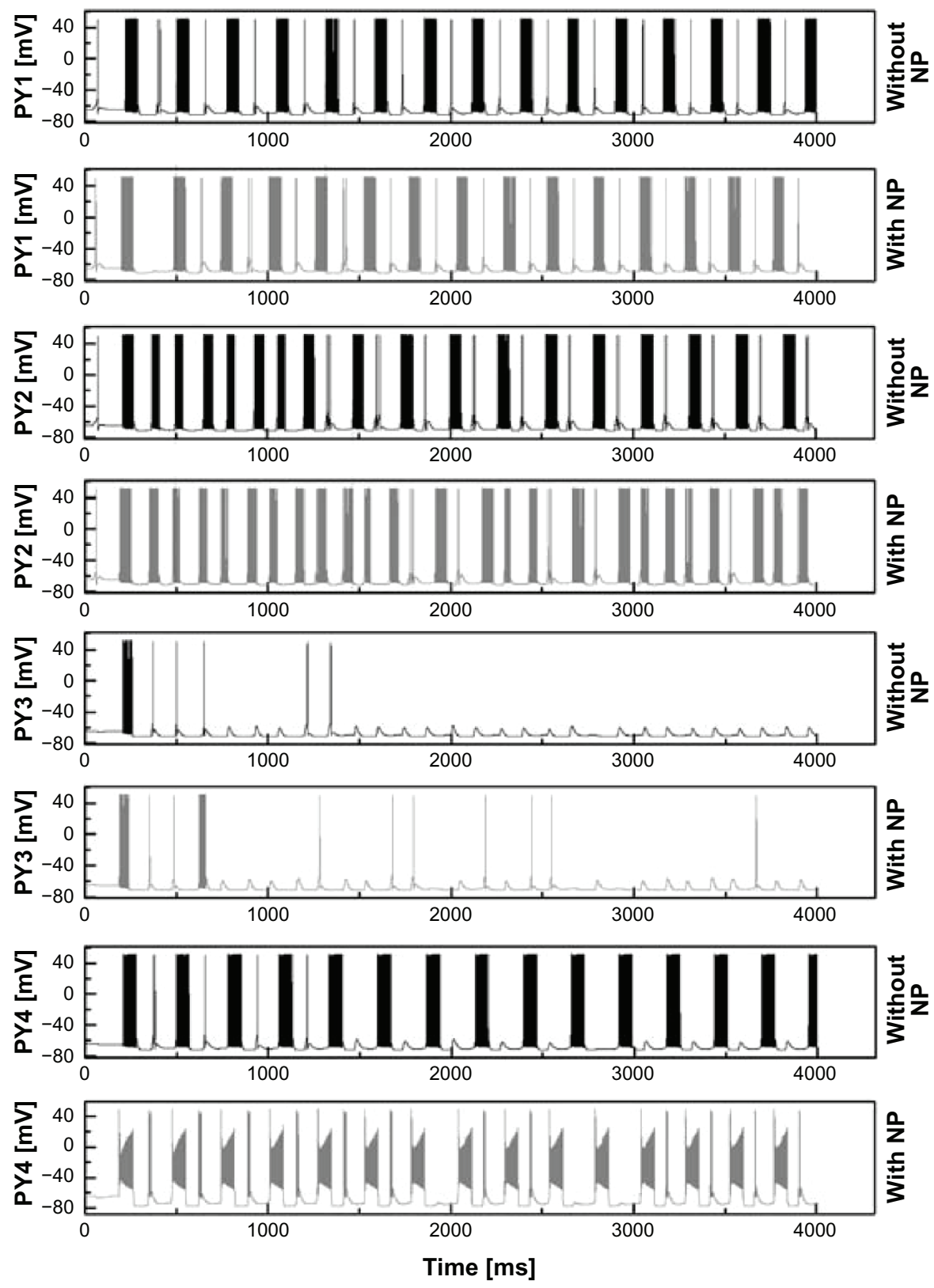

Figure 6 Firing pattern differences of pyramidal neurons.

Note: Differences in firing patterns of PYI, PY2, PY3, and PY4 neuron for 4 seconds before and after cAgNP application in thalamic neurons.

Abbreviations: PY, pyramidal neurons; $\mathrm{mV}$, millivolt; $\mathrm{cAgNP}$, coated silver nanoparticles; NP, nanoparticles; ms, milliseconds. 

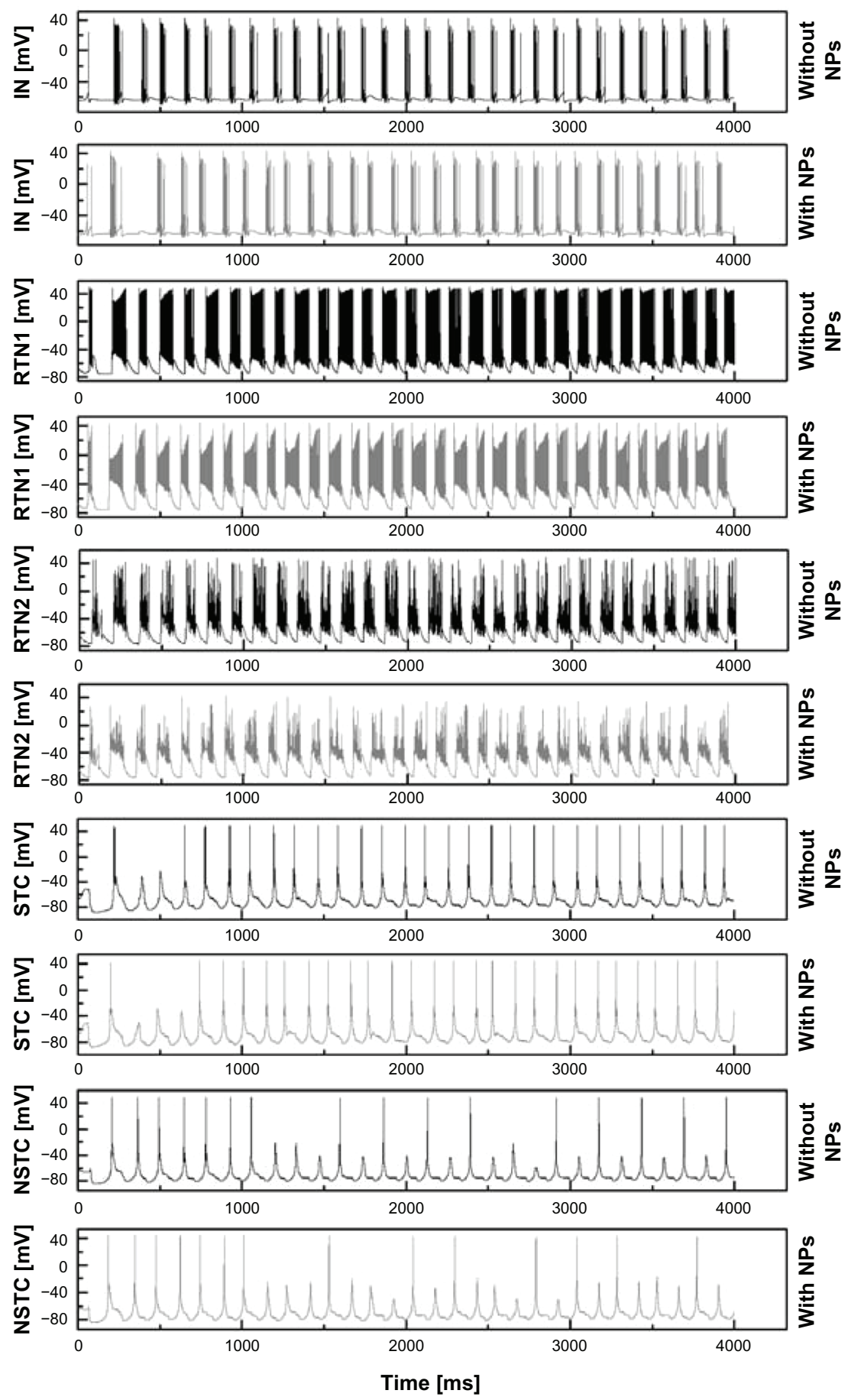

Figure 7 Firing pattern differences in IN, RTNI, RTN, STC, NSTC neurons.

Note: Differences in firing patterns of IN, RTNI, RTN2, STC, and NSTC neuron for 4 seconds before and after cAgNP application in RTN and STC neurons.

Abbreviations: IN, interneurons; mV, millivolt; STC, specific thalamic cells; NSTC, nonspecific thalamic cells; RTN, reticular thalamic cells; cAgNP, coated silver nanoparticles; ms, milliseconds, NP, nanoparticles.

altered. However, the lack of a rightward shift of the IV curves indicate that any effects on the voltage sensors or gating lead to failure to gate or a decreased channel conductance, which are not overcome by stronger depolarization. A shift in null potential, which might result from a change in ion selectivity, also cannot explain the reduced $\mathrm{I}_{\mathrm{Na}}$. We cannot distinguish between these two possibilities based on our data.
It is possible that $\mathrm{cAgNP}$ may produce mechanical effects on the ion channels leading to lower conductivity or fewer channels that reach the open state. An interaction of cAgNP with the reference electrode can be ruled out, since the holding current was not affected by cAgNP addition.

In any case, the net effects of $\mathrm{cAgNP}$ on neuronal feedback circuits will be a reduced excitability of affected cells, and 
Table 2 Changes in neuronal bursting after cAgNPs application

\begin{tabular}{|c|c|c|c|c|c|}
\hline Neuron type & $\begin{array}{l}\text { Interburst } \\
\text { interval (ms) }\end{array}$ & $\begin{array}{l}\sigma^{\mathrm{a}} \text { interburst } \\
\text { interval }(\mathrm{ms})\end{array}$ & $\begin{array}{l}\text { Interburst } \\
\text { frequency }(\mathrm{Hz})\end{array}$ & $\begin{array}{l}\text { Intraburst } \\
\text { frequency }(\mathrm{Hz})\end{array}$ & $\begin{array}{l}\sigma^{a} \text { intraburst } \\
\text { frequency }(\mathrm{Hz})\end{array}$ \\
\hline PYI before cAgNP application & 120 & 19 & 6.7 & 291 & 1 \\
\hline PYI after cAgNP application & 110 & 32 & 7.5 & 278.5 & 4.5 \\
\hline PY2 before cAgNP application & 96 & 33 & 6.5 & $27 \mid$ & 4 \\
\hline PY2 after cAgNP application & 93 & 33 & 7.75 & 266.5 & 6.5 \\
\hline PY4 before cAgNP application & 139 & 56 & 4.75 & 296 & 1 \\
\hline PY4 after cAgNP application & 125 & 57 & 6.7 & 691.5 & 2.5 \\
\hline IN before cAgNP application & 103 & 23 & 7.5 & 201 & 15.5 \\
\hline IN after cAgNP application & 89 & 27 & 8 & 139 & 2.5 \\
\hline RTNI before cAgNP application & 68 & 15 & 7.5 & 348.5 & 49.5 \\
\hline RTNI after cAgNP application & 65 & 8 & 7.75 & 366 & 72 \\
\hline RTN2 before cAgNP application & 75 & 15 & 7.5 & 293.5 & 35.5 \\
\hline RTN2 after cAgNP application & 69 & 12 & 7.75 & 332.5 & 19.5 \\
\hline
\end{tabular}

Note: ${ }^{\text {aStandard deviation. }}$

Abbreviations: cAgNP, coated silver nanoparticles; Hz, hertz; ms, milliseconds; PY, pyramidal neurons; IN, interneurons; NP, nanoparticles; RTN, reticular thalamic cells.

we have simulated these effects. The simulation indicates that application of $\mathrm{cAgNP}$ in the thalamus will result in dramatic changes in thalamocortical activity. This could occur, for instance, if cAgNP used as a drug carrier crossed the round window membrane of the cochlea and were retrograde transported. Praetorius et a $\mathrm{l}^{59}$ evaluated the safety and distribution of cyanin fluorescent dye (Cy3)-labeled silica NP in in vivo experiments by placing them on the round window membrane of adult mice. After 4 days, $\mathrm{SiO}_{2}-\mathrm{NP}$ signals could be found in the superior olivary complex. Their observation proposes a retrograde axonal transport for the applied NP. Our developed in silico model enables the investigation of potential effects of NP which enter the central nervous system.

Our simulations examine the systemic influences of cAgNP in neuronal systems. Though our computational model of the thalamocortical network is highly simplified and does not consider inputs or projections to other involved brain regions, it indicates that reduced excitability of a few neurons in such a circuit has dramatic effects on network activity. It is able to predict possible consequences of cAgNP introduction to neuronal feedback circuits.

The in vivo effects of such NP on any network will likely be complicated by additional effects of NP. We introduced changes in voltage-dependent sodium currents in our model. NP-induced changes in mechanisms affecting excitability, such as other ion channels, were not examined though effects on potassium channels have been reported ${ }^{60}$ In the future, we will investigate $\mathrm{cAgNP}$ effects on other aspects of membrane excitability and include these findings into our model.

\section{Conclusion}

The extension of our results in single chromaffin cells to neuronal circuits via modeling of the thalamocortical network allow us to make initial predictions as to what effects coated silver nanoparticles' suppression of sodium currents will have on thalamocortical circuits. Alteration of the properties of RTN, STC, or NSTC neurons, based on our HH model fits of $\mathrm{I}_{\mathrm{Na}}$ after treatment with cAgNP, shows that NP brought into contact with few cells of a neuronal feedback circuit can dramatically alter network rhythms of large neuronal populations.

\section{Disclosure}

The authors report no conflicts of interest in this work.

\section{References}

1. Gupta AK, Gupta M. Synthesis and surface engineering of iron oxide nanoparticles for biomedical applications. Biomaterials. 2005;26(18): 3995-4021.

2. Zhang Y, Satterlee A, Huang L. In vivo gene delivery by nonviral vectors: overcoming hurdles? Mol Ther. 2012;20(7):1298-1304.

3. Lamarre B, Ryadnov MG. Self-assembling viral mimetics: one long journey with short steps. Macromol Biosci. 2011;11(4):503-513.

4. Chithrani B, Ghazani A, Chan W. Determining the size and shape dependence of gold nanoparticle uptake into mammalian cells. Nano Lett. 2006;6(4):662-668.

5. Jiang W, Kim BY, Rutka JT, Chan WC. Nanoparticle-mediated cellular response is size-dependent. Nat Nanotechnol. 2008;3(3):145-150.

6. Unfried K, Albrecht C, Klotz L, Von Mikecz A, Grether-Beck S, Schins R. Cellular responses to nanoparticles: target structures and mechanisms. Nanotoxicology. 2007;1(1):52-71.

7. Oberdörster G. Safety assessment for nanotechnology and nanomedicine: concepts of nanotoxicology. J Intern Med. 2010;267(1):89-105.

8. El-Ansary A, Al-Daihan S. On the toxicity of therapeutically used nanoparticles: an overview. J Toxicol. 2009;2009:754810.

9. Wijnhoven S, Peijnenburg W, Herberts C, et al. Nano-silver - a review of available data and knowledge gaps in human and environmental risk assessment. Nanotoxicology. 2009;3(2):109-138.

10. Xu L, Zhao J, Zhang T, Ren G, Yang Z. In vitro study on influence of nanoparticles of $\mathrm{CuO}$ on $\mathrm{CA} 1$ pyramidal neurons of rat hippocampus potassium currents. Environ Toxicol. 2009;24(3):211-217.

11. Zhao J, Xu L, Zhang T, Ren G, Yang Z. Influences of nanoparticle zinc oxide on acutely isolated rat hippocampal CA3 pyramidal neurons. Neurotoxicology. 2009;30(2):220-230. 
12. Liu Z, Ren G, Zhang T, Yang Z. Action potential changes associated with the inhibitory effects on voltage-gated sodium current of hippocampal CA1 neurons by silver nanoparticles. Toxicology. 2009;264(3): 179-184.

13. Hodgkin A, Huxley A. A quantitative description of membrane current and its application to conduction and excitation in nerve. $J$ Physiol. 1952;117(4):500-544.

14. Price K, Storn R, Lampinen J, editors. Differential Evolution: A Practical Approach to Global Optimization. Heidelberg, Germany: Springer-Verlag; 2005.

15. Llinás R, Ribary U. Coherent $40-\mathrm{Hz}$ oscillation characterizes dream state in humans. Proc Natl Acad Sci U S A. 1993;90(5): 2078-2081.

16. Llinás R, Ribary U, Joliot M, Wang XJ. Content and context in temporal thalamocortical binding. In: Buzsáki G, Christen Y, editors. Temporal Coding in the Brain (Research and Perspectives in Neurosciences). Heidelberg, Germany: Springer-Verlag; 1994:252-272.

17. Llinás R, Ribary U, Contreras D, Pedroarena C. The neuronal basis for consciousness. Philos Trans R Soc Lond B Biol Sci. 1998;353(1377): 1841-1849.

18. Llinás R, Leznik E, Urbano FJ. Temporal binding via cortical coincidence detection of specific and nonspecific thalamocortical inputs: a voltage-dependent dye-imaging study in mouse brain slices. Proc Natl Acad Sci U S A. 2002;99(1):449-454.

19. Pellegrino T, Manna L, Kudera S, et al. Hydrophobic nanocrystals coated with an amphiphilic polymer shell: a general route to water soluble nanocrystals. Nano Lett. 2004;4(4):703-707.

20. Fenwick EM, Marty A, Neher E. A patch clamp study of bovine chromaffin cells and of their sensitivity to acetylcholine. J Physiol. 1982; 331:577-597.

21. Kobayashi H, Shiraishi S, Yanagita T, et al. Regulation of voltagedependent sodium channel expression in adrenal chromaffin cells: involvement of multiple calcium signaling pathways. Ann N Y Acad Sci. 2002;971:127-134.

22. Tischler AS. Chromaffin cells as models of endocrine cells and neurons. Ann N Y Acad Sci. 2002;971:366-370.

23. Goldin AL, Barchi RL, Caldwell JH, et al. Nomenclature of voltagegated sodium channels. Neuron. 2000;28(2):365-368.

24. Catterall WA, Goldin AL, Waxman SG. International union of pharmacology. XLVII. Nomenclature and structure-function relationships of voltage-gated sodium channels. Pharmacol Rev. 2005;57(4): $397-409$.

25. Goldin AL. Resurgence of sodium channel research. Annu Rev Physiol. 2001;63:871-894.

26. Lorincz A, Nusser Z. Molecular identity of dendritic voltage-gated sodium channels. Science. 2010;328(5980):906-909.

27. Royeck M, Horstmann M, Remy S, Reitze M, Yaari Y, Beck H. Role of axonal NaV1.6 sodium channels in action potential initiation of CA1 pyramidal neurons. J Neurophysiol. 2008;100(4):2361-2380.

28. Toledo-Aral JJ, Moss BL, He Z, et al. Identification of PN1, a predominant voltage-dependent sodium channel expressed principally in peripheral neurons. Proc Natl Acad Sci U S A. 1997;94(4):1527-1532.

29. Malmivuo J, Plonsey R, editors. Bioelectromagnetism: Principles and Applications of Bioelectric and Biomagnetic Fields. New York: Oxford University Press; 1995.

30. Hamill O, Marty A, Neher E, Sakmann B, Sigworth F. Improved patch clamp techniques for high-resolution current recording from cells and cell-free membrane patches. Pflugers Arch. 1981;391(2):85-100.

31. Shepherd GM, editor. The Synaptic Organization of the Brain, 5th ed. Oxford, New York: Oxford University Press; 2001.

32. Jones EG. Thalamic circuitry and thalamocortical synchrony. Philos Trans R Soc Lond B Biol Sci. 2002;357(1428):1659-1673.

33. Singer W. Neuronal synchrony: a versatile code for the definition of relations? Neuron. 1999;24(1):49-65.

34. Hughes SW, Errington A, Lörincz ML, et al. Novel modes of rhythmic burst firing at cognitively relevant frequencies in thalamocortical neurons. Brain Res. 2008;1235:12-20.
35. Gray CM, Singer W. Stimulus-specific neuronal oscillations in orientation columns of cat visual cortex. Proc Natl Acad Sci U S A. 1989;86(5):1698-1702.

36. Ribary U, Ioannides AA, Singh KD, et al. Magnetic field tomography of coherent thalamocortical $40-\mathrm{Hz}$ oscillations in humans. Proc Natl Acad Sci U S A. 1991;88(24):11037-11041

37. Singer W. Synchronization of cortical activity and its putative role in information processing and learning. Annu Rev Physiol. 1993;55: 349-374.

38. Gregoriou G, Gotts S, Zhou H, Desimone R. High-frequency, longrange coupling between prefrontal and visual cortex during attention. Science. 2009;324(5931):1207-1210.

39. Suk J, Ribary U, Cappell J, Yamamoto T, Llinás R. Anatomical localization revealed by MEG recordings of the human somatosensory system. Electroencephalogr Clin Neurophysiol. 1991;78(3):185-196.

40. Gray CM, McCormick DA. Chattering cells: superficial pyramidal neurons contributing to the generation of synchronous oscillations in the visual cortex. Science. 1996;274(5284):109-113.

41. Steriade M, Timofeev I, Dürmüller N, Grenier F. Dynamic properties of corticothalamic neurons and local cortical interneurons generating fast rhythmic (30-40 Hz) spike bursts. J Neurophysiol. 1998;79(1): 483-490.

42. Brumberg JC, Nowak LG, McCormick DA. Ionic mechanisms underlying repetitive high-frequency burst firing in supragranular cortical neurons. J Neurosci. 2000;20(13):4829-4843.

43. Wang XJ, Golomb D, Rinzel J. Emergent spindle oscillations and intermittent burst firing in a thalamic model: specific neuronal mechanisms. Proc Natl Acad Sci U S A. 1995;92(12):5577-5581.

44. Wang XJ. Calcium coding and adaptive temporal computation in cortical pyramidal neurons. J Neurophysiol. 1998;79(3):1549-1566.

45. Golomb D, Wang XJ, Rinzel J. Propagation of spindle waves in a thalamic slice model. J Neurophysiol. 1996;75(2):750-769.

46. Golomb D, Shedmi A, Curtu R, Ermentrout GB. Persistent synchronized bursting activity in cortical tissues With low-magnesium concentration: a modeling study. J Neurophysiol. 2006;95(2):1049-1067.

47. Wang XJ, Buzsáki G. Gamma oscillation by synaptic inhibition in a hippocampal interneuronal network model. J Neurosci. 1996;16(20): 6402-6413.

48. Destexhe A, Bal T, McCormick DA, Sejnowski TJ. Ionic mechanisms underlying synchronized oscillations and propagating waves in a model of ferret thalamic slices. J Neurophysiol. 1996;76(3): 2049-2070.

49. Bazhenov M, Timofeev I, Steriade M, Sejnowski TJ. Cellular and network models for intrathalamic augmenting responses during $10-\mathrm{Hz}$ stimulation. J Neurophysiol. 1998;79(5):2730-2748.

50. Golomb D, Amitai Y. Propagating neuronal discharges in neocortical slices: computational and experimental study. J Neurophysiol. 1997; 78(3):1199-1211.

51. Destexhe A, Contreras D, Sejnowski TJ, Steriade M. A model of spindle rhythmicity in the isolated thalamic reticular nucleus. J Neurophysiol. 1994;72(2):803-818.

52. Destexhe A, Contreras D, Steriade M, Sejnowski TJ, Huguenard JR. In vivo, in vitro, and computational analysis of dendritic calcium currents in thalamic reticular neurons. J Neurosci. 1996;16(1): 169-185.

53. Destexhe A, Contreras D, Steriade M. Mechanisms underlying the synchronizing action of corticothalamic feedback through inhibition of thalamic relay cells. J Neurophysiol. 1998;79(2):999-1016.

54. Bazhenov M, Timofeev I, Steriade M, Sejnowski TJ. Model of thalamocortical slow-wave sleep oscillations and transitions to activated states. J Neurosci. 2002;22(19):8691-8704.

55. Destexhe A, Mainen ZF, Sejnowski TJ. Kinetic models of synaptic transmission. In: Koch C, Segev I, editors. Methods in Neuronal Modeling: From Ions to Networks (Computational Neuroscience). 2nd ed. Cambridge: The MIT Press; 1998:1-25.

56. Wang XJ, Rinzel J. Alternating and synchronous rhythms in reciprocally inhibitory model neurons. Neural Comput. 1992;4(1):84-97. 
57. Golomb D, Wang XJ, Rinzel J. Synchronization properties of spindle oscillations in a thalamic reticular nucleus model. $J$ Neurophysiol 1994;72(3):1109-1126.

58. Destexhe A, Mainen ZF, Sejnowski TJ. An efficient method for computing synaptic conductances based on a kinetic model of receptor binding. Neural Comput. 1994;6(1):14-18.
59. Praetorius M, Brunner C, Lehnert, et al. Transsynaptic delivery of nanoparticles to the central auditory nervous system. Acta Otolaryngol. 2007;127(5):486-490.

60. Liu Z, Ren G, Zhang T, Yang Z. The inhibitory effects of nano-Ag on voltage-gated potassium currents of hippocampal CA1 neurons. Environ Toxicol. 2011;26(5):552-558. 


\section{Supplementary materials}

The Llinás model as basis for the developed corticothalamic network

Llinás et al suggested a reasonably detailed model of thalamocortical interaction and binding. ${ }^{1-4}$ Their principal finding is that the intrinsic electrical properties of neurons and the dynamic events resulting from their connectivity cause global resonant states. Resonant states in the network will change by just small alterations in the neural signaling characteristics. The Llinás model exposing the thalamocortical circuit can be found in Llinás et al. ${ }^{3}$ For our purpose, we focus on two types of thalamic cells: first, specific thalamic cells (STC), also known as thalamic core cells due to their focused projection to an individual cortical area and, second, intralaminar non-specific thalamic cells (NSTC), also known as thalamic matrix cells as they project across larger neocortical areas in a more dispersed way. ${ }^{5}$ We utilized two thalamocortical resonant loops for our model. The description of neural interactions and dynamics can be found in the subsequent section. It was proposed by Llinás et al that none of these two systems alone is able to generate cognition, and consistent with this model, damage to the nonspecific thalamus induces deep disturbances of consciousness while damage to the specific systems causes loss of particular modality. ${ }^{3}$ Their statement implies that these two systems can only generate a cognitive experience synced, based on the summation of nonspecific and specific activity along the dendritic tree of the cortical element, by coincidence detection at the pyramidal neuron. ${ }^{3,4}$ To conclude, the system operates on the basis of thalamocortical resonant columns that can support global cognitive experiences. In this context, the specific system provides the content that relates to the external world while the nonspecific system would give rise to the temporal conjunction (binding circuit). This well explored and accepted model serves as the theoretical fundament for our investigations on nanoparticle-induced signaling modifications in neuronal circuits.

\section{References}

1. Llinás R, Ribary U. Coherent $40-\mathrm{Hz}$ oscillation characterizes dream state in humans. Proc Natl Acad Sci U S A. 1993;90(5):2078-2081.

2. Llinás R, Ribary U, Joliot M, Wang XJ. Content and context in temporal thalamocortical binding. In: Buzsáki G, Christen Y, editors. Temporal Coding in the Brain (Research and Perspectives in Neurosciences). Heidelberg, Germany: Springer-Verlag; 1994:252-272.

3. Llinás R, Ribary U, Contreras D, Pedroarena C. The neuronal basis for consciousness. Philos Trans R Soc Lond B Biol Sci. 1998;353(1377): 1841-1849.

4. Llinás R, Leznik E, Urbano FJ. Temporal binding via cortical coincidence detection of specific and nonspecific thalamocortical inputs: a voltagedependent dye-imaging study in mouse brain slices. Proc Natl Acad Sci US A. 2002;99(1):449-454.

5. Shepherd GM, editor. The Synaptic Organization of the Brain, 5th ed. Oxford, New York: Oxford University Press; 2001.

Table SI Amplitudes of $\mathrm{I}_{\mathrm{Na}}$ before and after $\mathrm{cAgNP}$ addition as total values

\begin{tabular}{llllll}
\hline $\begin{array}{l}\text { cAgNP } \\
\text { concentration }\end{array}$ & $\begin{array}{l}\tilde{\mathbf{x}}^{\mathrm{a}} \text { before cAgNP in } \\
\text { pA and (normalized) }\end{array}$ & $\begin{array}{l}\tilde{\mathbf{x}} \text { after cAgNP in pA } \\
\text { and (normalized) }\end{array}$ & $\begin{array}{l}\sigma^{\mathrm{b}} \text { before cAgNP in pA } \\
\text { and (normalized) }\end{array}$ & $\begin{array}{l}\sigma \text { after cAgNP in pA } \\
\text { and (normalized) }\end{array}$ & $\begin{array}{l}\Delta \tilde{\mathbf{x}}^{\mathrm{c}} \text { in pA and } \\
(\text { normalized) }\end{array}$ \\
\hline $\mathrm{I} / \mathrm{I} 00(\mathrm{I} 3 \mu \mathrm{Mol})$ & $634.2(\mathrm{I})$ & $579.3(0.91)$ & $86(0.14)$ & $77.5(0.12)$ & $54.90(0.09)$ \\
$\mathrm{I} / 80(16 \mu \mathrm{Mol})$ & $613.4(\mathrm{I})$ & $472.3(0.77)$ & $116.6(0.19)$ & $67.5(0.1 \mathrm{I})$ & $141.1(0.23)$ \\
$\mathrm{I} / 30(43 \mu \mathrm{Mol})$ & $731.9(\mathrm{I})$ & $382.9(0.52)$ & $129.8(0.18)$ & $66.6(0.09)$ & $349(0.48)$ \\
$\mathrm{I} / \mathrm{I} 0(130 \mu \mathrm{Mol})$ & $824.7(\mathrm{I})$ & $384.85(0.47)$ & $105.6(0.13)$ & $84.3(0.10)$ & $439.9(0.53)$ \\
$\mathrm{I} / \mathrm{I}(\mathrm{I} .3 \mathrm{mMol})$ & $609.3(\mathrm{I})$ & $190.4(0.3 \mathrm{I})$ & $81.4(0.13)$ & $141.28(0.23)$ & $418.90(0.69)$ \\
\hline
\end{tabular}

Notes: $\mathrm{a} \tilde{\mathrm{x}}=$ Average amplitude expressed as median value in $\mathrm{pA} ;{ }^{\mathrm{b}} \sigma=$ Standard deviation; ${ }^{\mathrm{c}} \Delta \tilde{\mathrm{x}}=$ Difference in median between controls and cAgNP exposed cells. Amplitudes of $\mathrm{I}_{\mathrm{NA}}$ before and after cAgNP addition (holding potential $-70 \mathrm{mV}$, depolarization potential $-20 \mathrm{mV}$ ). The protocols of 80 controls and $45 \mathrm{cAgNP}$ exposed chromaffin cells were collected to serve as experimental data fundament, in particular $1.3 \mathrm{mMol}=15$ controls +6 affected; $13 \mu \mathrm{Mol}=15$ controls +10 affected; $16 \mu \mathrm{Mol}=10$.

Abbreviations: $\mathrm{cAgNP}$, silver coated nanoparticles; $\mathrm{mV}$, millivolt; $\mathrm{pA}$, picoampere.

\section{Publish your work in this journal}

The International Journal of Nanomedicine is an international, peerreviewed journal focusing on the application of nanotechnology in diagnostics, therapeutics, and drug delivery systems throughout the biomedical field. This journal is indexed on PubMed Central, MedLine, CAS, SciSearch ${ }^{\circledR}$, Current Contents ${ }^{\circledR} /$ Clinical Medicine,
Journal Citation Reports/Science Edition, EMBase, Scopus and the Elsevier Bibliographic databases. The manuscript management system is completely online and includes a very quick and fair peer-review system, which is all easy to use. Visit http://www.dovepress.com/ testimonials.php to read real quotes from published authors. 